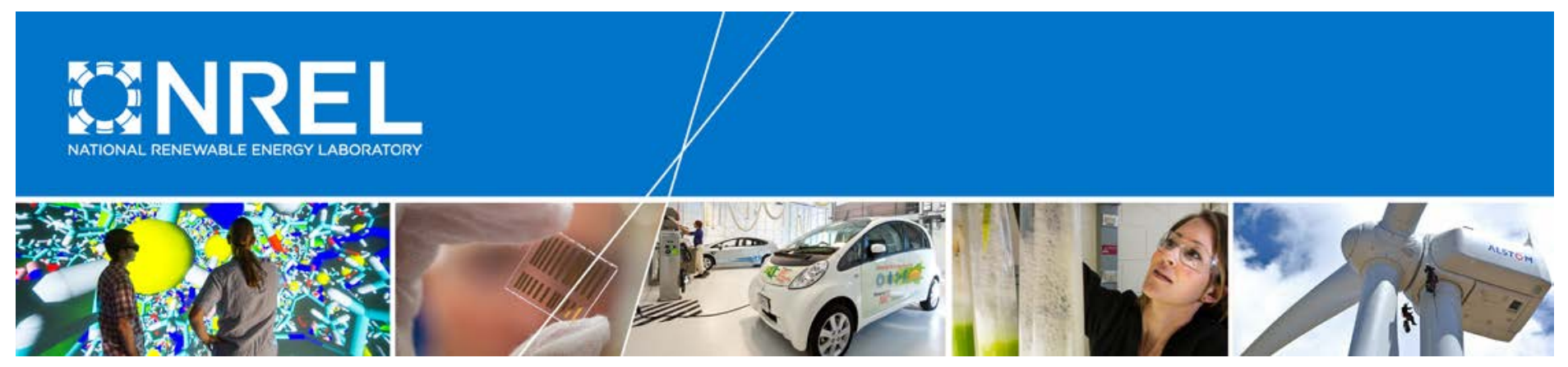

\title{
Outdoor Irrigation Measurement and Verification Protocol
}

Kate McMordie Stoughton

Pacific Northwest National Laboratory

Jorge Figueroa

Western Resource Advocates

NREL Technical Monitor: Charles Kurnik

NREL is a national laboratory of the U.S. Department of Energy Office of Energy Efficiency \& Renewable Energy Operated by the Alliance for Sustainable Energy, LLC

This report is available at no cost from the National Renewable Energy Laboratory (NREL) at www.nrel.gov/publications.

\section{Subcontract Report}

NREL/SR-7A40-70218

December 2017 


\section{Outdoor Irrigation Measurement and Verification Protocol}

Kate McMordie Stoughton

Pacific Northwest National Laboratory

Jorge Figueroa

Western Resource Advocates

NREL Technical Monitor: Charles Kurnik

Prepared under Subcontract No. TSA-17-898/285 1392
NREL is a national laboratory of the U.S. Department of Energy Office of Energy Efficiency \& Renewable Energy Operated by the Alliance for Sustainable Energy, LLC

This report is available at no cost from the National Renewable Energy Laboratory (NREL) at www.nrel.gov/publications.

\section{Subcontract Report}

NREL/SR-7A40-70218

December 2017

Contract No. DE-AC36-08GO28308
National Renewable Energy Laboratory 15013 Denver West Parkway

Golden, CO 80401

303-275-3000 • www.nrel.gov 


\title{
This publication was reproduced from the best available copy submitted by the subcontractor and received no editorial review at NREL.
}

\begin{abstract}
NOTICE
This report was prepared as an account of work sponsored by an agency of the United States government. Neither the United States government nor any agency thereof, nor any of their employees, makes any warranty, express or implied, or assumes any legal liability or responsibility for the accuracy, completeness, or usefulness of any information, apparatus, product, or process disclosed, or represents that its use would not infringe privately owned rights. Reference herein to any specific commercial product, process, or service by trade name, trademark, manufacturer, or otherwise does not necessarily constitute or imply its endorsement, recommendation, or favoring by the United States government or any agency thereof. The views and opinions of authors expressed herein do not necessarily state or reflect those of the United States government or any agency thereof.
\end{abstract}

This report is available at no cost from the National Renewable Energy Laboratory (NREL) at www.nrel.gov/publications.

Available electronically at SciTech Connect http:/www.osti.gov/scitech

Available for a processing fee to U.S. Department of Energy and its contractors, in paper, from:

\author{
U.S. Department of Energy \\ Office of Scientific and Technical Information \\ P.O. Box 62 \\ Oak Ridge, TN 37831-0062 \\ OSTI http://www.osti.gov \\ Phone: 865.576.8401 \\ Fax: 865.576.5728 \\ Email: reports@osti.gov
}

Available for sale to the public, in paper, from:

\author{
U.S. Department of Commerce \\ National Technical Information Service \\ 5301 Shawnee Road \\ Alexandria, VA 22312 \\ NTIS http://www.ntis.gov \\ Phone: 800.553 .6847 or 703.605 .6000 \\ Fax: 703.605.6900 \\ Email: orders@ntis.gov
}




\section{Outdoor Irrigation Measurement and Verification Protocol}

Guidelines for Energy Service Companies and Water Efficiency Service Companies to Determine Water Savings of Outdoor Irrigation Efficiency Measures for Use in Performance Contracts

\section{August 2017}

KL McMordie Stoughton

SA Loper

JR Figueroa

Prepared by Pacific Northwest National Laboratory and Western Resource Advocates as model guidelines for the State Performance Contracting Programs of Colorado, Nevada, and New Mexico. 


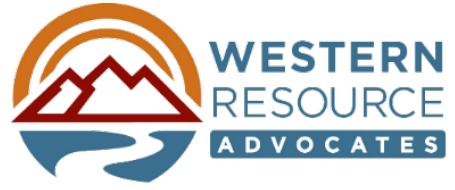

PROTECTING THE WEST'S LAND, AIR \& WATER

\section{Pacific Northwest} NATIONAL LABORATORY

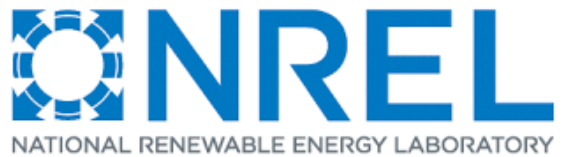

Western Resource Advocates has spent more than 25 years protecting the West's land, air, and water so that our communities thrive in balance with nature. We use law, science, and economics to craft innovative solutions to the most pressing conservation issues in the region.

The Pacific Northwest National Laboratory's mission is to transform the world through courageous discovery and innovation. For more than 50 years, PNNL has advanced the frontiers of science and engineering in the service of the nation and the world, translating discoveries into tools and technologies in science, energy, the environment, and national security.

The National Renewable Energy Laboratory focuses on creative answers to today's energy challenges. From breakthroughs in fundamental science to new clean technologies to integrated energy systems that power our lives, NREL researchers are transforming the way the nation and the world use energy. 


\section{Outdoor Irrigation Measurement and Verification Technical Advisory Group}

$\begin{array}{ll}\text { Brent Q. Mecham } & \text { Industry Development Director, Irrigation Association } \\ \text { Ben Slick } & \text { Senior Vice President of Business Development, HydroPoint } \\ \text { Cable Jones } & \text { Project Developer, Water Management, Inc. } \\ \text { Niffy Ovuworie } & \text { M\&V Program Manager for the Rocky Mountain Region, McKinstry } \\ \text { Megan Ferguson } & \text { Energy Engineer, Siemens Industry, Inc. } \\ \text { Patrick Watson } & \text { Conservation Services Administrator, Southern Nevada Water Authority } \\ \text { Paul Basset } & \text { Senior Vice-President and Chief Technology Officer, Water Savers, LLC } \\ \text { Richard Chapman } & \text { President, Smart Use, LLC } \\ \begin{array}{l}\text { Philip Neff } \\ \text { Scott Winter }\end{array} & \text { Engineering Manager, Honeywell Energy Services Group of North America } \\ \text { William Travers } & \text { Lead Water Conservation Specialist, Colorado Springs Utilities } \\ & \text { Sr. Project Developer, NORESCO } \\ \text { Technical Lead } & \\ \text { Kate McMordie Stoughton } & \text { Water Efficiency Engineer, Pacific Northwest National Laboratory } \\ \text { Project Co-Leads } & \\ \text { Jorge Figueroa } & \\ \text { Taylor Lewis, PE } & \text { Senior Water Policy Analyst, Western Resource Advocates } \\ \text { Senior Advisors } & \text { Program Engineer, Colorado Energy Office } \\ \text { Chuck Kurnik } & \end{array}$

\section{Steering Committee Members}

Water, Measurement and Verification (M\&V) Guidelines, and State Performance Contracts Project

$\begin{array}{ll}\text { Donald Gilligan } & \text { President, National Association of Energy Service Companies } \\ \text { Mary Ann Dickinson } & \text { President and CEO, Alliance for Water Efficiency } \\ \text { John Canfield } & \text { President, Trident Energy Services } \\ \text { Chris Halpin } & \text { President, Celtic Energy } \\ \text { Patrick Watson } & \text { Conservation Services Administrator, Southern Nevada Water Authority } \\ \text { Carlos Bustos } & \text { Water Conservation Program Manager, Albuquerque Bernalillo County Water Utility Authority } \\ \text { Frank Kinder } & \text { Senior Conservation Specialist, Colorado Springs Utilities } \\ \text { Paul Matuska } & \text { Manager, Water Accounting and Verification Group, U.S. Bureau of Reclamation } \\ \text { William D. Taylor } & \text { Private Sector Co-Chair, Energy Services Coalition-Nevada Chapter } \\ \text { Oscar Rangel } & \text { Private Sector Co-Chair, Energy Services Coalition-Colorado Chapter } \\ \text { Scott Griffith } & \text { Private Sector Co-Chair, Energy Services Coalition-New Mexico Chapter } \\ \text { Harold Trujillo } & \text { Chief, New Mexico Energy Technology and Engineering Bureau, New Mexico EPC Program } \\ \text { Kelly Thomas } & \text { Energy Program Manager, Nevada Governor's Office of Energy, Nevada EPC Program } \\ \text { Taylor Lewis, PE } & \text { Program Engineer, Colorado Energy Office, Colorado EPC Program }\end{array}$




\section{Acknowledgements}

The authors would thank all of the experts who participated in the Outdoor Irrigation Technical Advisory Group; we are grateful for their invaluable time and generous support. We also genuinely appreciate, and are fortunate to have, the excellent and gracious guidance of the Colorado Energy Office, Chuck Kurnik (NREL), Linda Smith (9Kft Strategies in Energy), the project's Steering Committee, and Jim Zarske (Nexant, Inc.; who suggested the use of the Uniform Methods Project approach for this project). The authors take full responsibility for any error found in these guidelines, and the participation of the above-listed entities in the Technical Advisory Group does not imply their agreement with or endorsement of the concepts, analysis, methodologies, or conclusions presented in this document.

This work was funded through a grant from the Rosin Fund - Environment Program. 


\section{Table of Contents}

1.0 Acronyms, Abbreviations, and Definitions ........................................................... 1

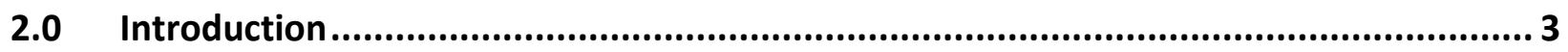

3.0 Measure Description ................................................................................................. 3

4.0 Measurement and Verification Plan Elements .......................................................... 4

4.1 Measurement and Verification Method ..............................................................................

4.2 Measure Description and Measurement Boundary.................................................................

4.3 Baseline and Post-Installation Condition ..........................................................................5

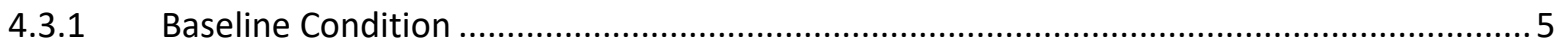

4.3.2 Post-Installation Condition .............................................................................. 5

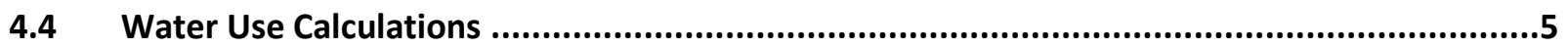

4.5 Data Categories.........................................................................................................

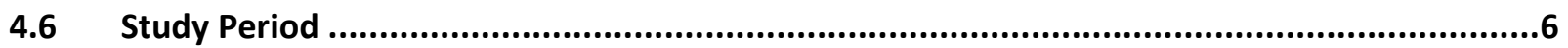

4.7 Measurement Period......................................................................................7

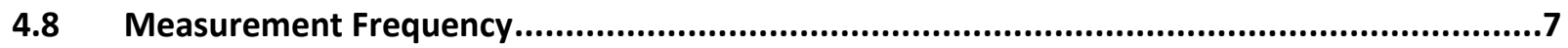

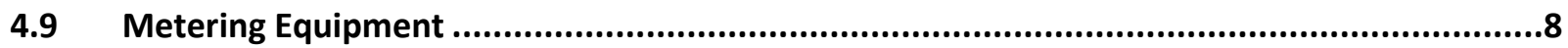

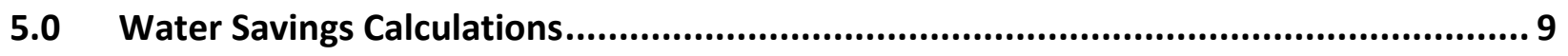

5.1 Baseline Water Use ...................................................................................................

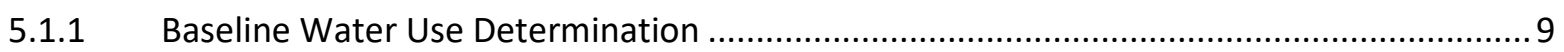

5.1.2 Baseline Normalization ..................................................................................... 11

5.2 Post-Installation Water Use Determination .....................................................................12

5.3 Data Normalization .....................................................................................................13

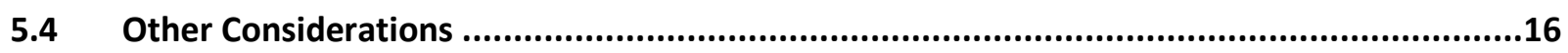

6.0 Commissioning Protocol ......................................................................................... 17

\section{Tables}

Table 1. Sample Normalization of Post-Installation Water Use in Aurora, Colorado.

\section{Figures}

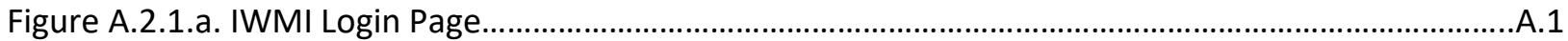

Figure A.2.1.b. IWMI User-Specified Location and Climate Variables.....................................................2

Figure A.2.2. Example of IWMI Climate Variable Outputs Need for Normalization......................................3

Figure A.2.3. Example of an Online Latitude and Longitude Converter for a User-Specified Address......A.4 


\subsection{Acronyms, Abbreviations, and Definitions}

ASBE

CAWQuer

Climate normal

CoAgMet

Commissioning

Effective precipitation

ESCO

Evapotranspiration (ET)

Hydrozone

Irrigation efficiency

IPMVP

IWMI

$M \& V$

Measurement boundary

Measurement frequency

Measurement period

NOAA

Plant factor

Reference ET (ETo)

Study period
American Society of Agricultural and Biological Engineers

Climate Atlas Web Query (online tool and database)

Average weather conditions for a given location that is over the latest three-decade period

Colorado Agricultural Meteorological Network

The process whereby the measure improvements made to the equipment or the control system have been verified to comply with the approved plan, and visually inspected and evaluated for proper operation

The amount of rainfall that is added and stored in the soil

energy service company (performance contractor)

The combination of loss of water due to evaporation from soil and plant surfaces and the amount of water transpired by the plant over a given time frame

A distinct area of the landscape that receives irrigation from the same system

The percentage of irrigation water that is stored in the soil and available for use by the landscape (as compared to the total amount of water provided to the landscape)

International Performance Measurement and Verification Protocol

International Water Management Institute

measurement and verification

The specific landscape areas that are impacted by the WCM and monitored for water savings

The number of measurements that will be collected over the measurement period to determine water-use savings

The time frame within which water use is monitored, defined by the irrigation season

National Oceanic and Atmospheric Administration

The fraction of reference evapotranspiration required by the plant type for acceptable appearance

The loss of water from the defined vegetated surface (e.g., alfalfa grass) which serves as an evaporative index by which evapotranspiration can be predicted for a range of vegetation and surface conditions

The total time frame that water use will be monitored per the contractual arrangement for the baseline and post-installation periods 
WCM

WESCO water conservation measure

water efficiency service company (performance contractor) 


\subsection{Introduction}

This measurement and verification (M\&V) protocol provides procedures for energy service companies (ESCOs) and water efficiency service companies (WESCOs) to determine water savings resulting from water conservation measures (WCMs) in energy performance contracts associated with outdoor irrigation efficiency projects. The water savings are determined by comparing the baseline water use to the water use after the WCM has been implemented. This protocol outlines the basic structure of the M\&V plan, and details the procedures to use to determine water savings. It is vital that the customer reviews the M\&V plan thoroughly and agrees to the procedures used by the ESCO and WESCO to collect data and measure water savings.

The procedures presented in this protocol are performance based. In performance contracts, ESCOs and WESCOs are required to measure the amount of water savings directly and do not have to prove the effectiveness of the measure itself. This protocol does not cover other cost streams such as operation and maintenance or energy costs.

\subsection{Measure Description}

This protocol specifies M\&V requirements for WCMs associated with improving the efficiency of irrigation systems. Irrigation systems include all components that deliver and control the application of supplemental water in landscapes. System components include piping infrastructure, valves, sprinkler heads, and irrigation controls. The WCMs that are covered by this M\&V protocol include, but are not limited to, the following.

\section{Irrigation System Efficiency Improvements}

The objective of this measure is to increase irrigation system efficiency by improving the uniform distribution of water to meet the landscape irrigation requirements and minimize waste and losses from the system. ${ }^{1}$ This WCM category can include measures such as reconfiguring the irrigation system, repairing system components, repairing system leaks, and replacing irrigation systems with more efficient technology such as drip irrigation and subsurface irrigation.

\section{Advanced Controls}

Irrigation controllers manage the application of water to a landscape. This measure includes installing advanced controllers that use real-time data to irrigate landscape based on local conditions. Such measures can reduce overall watering times, thereby decreasing water use. Advanced controllers include weather-based systems that use weather data to calculate evapotranspiration (ET) to determine the landscape's current irrigation requirements. Another type of advanced controller is the soil-moisturebased controller, which uses real-time soil moisture data and adjusts the irrigation schedule to meet the specific water needs.

\footnotetext{
${ }^{1}$ Irrigation efficiency is defined as the percentage of irrigation water that is stored in the soil and available for use by the landscape as compared to the total amount of water provided to the landscape.
} 


\section{Real-Time Sensors}

Real-time sensors monitor live conditions of the landscape, and can temporarily suspend irrigation when irrigation is not optimal. Examples of real-time sensors include rain, wind, and freeze sensors. These typically are tied into an automated control system to optimize the irrigation schedule, thereby reducing the overall amount of irrigation of the landscape.

Another type of real-time sensor is the flow sensor. Flow sensors monitor water flowing in the irrigation distribution pipes that can detect abnormal flow conditions that could indicate a system problem. The flow sensor can interface with an irrigation controller to suspend irrigation when needed.

\subsection{Measurement and Verification Plan Elements}

In a performance contract, the ESCO and the WESCO are required to develop a plan that specifies how the $M \& V$ will be performed. This section provides the basic structure of the $M \& V$ plan.

\subsection{Measurement and Verification Method}

The International Performance Measurement and Verification Protocol (IPMVP) has four options (A, B, C, and D) that can be used to verify the savings of measures.

For outdoor irrigation efficiency measures, the recommended IPMVP option to verify water savings is Option B, "Retrofit Isolation."

The objective of Option B - Retrofit Isolation - is to verify performance by measuring the system usage, which increases the accuracy of the verified savings. The retrofit isolation method uses real-time field measurements of the irrigation system to verify the savings, whereby short-term or continuous measurements are taken throughout the study period. The flow of each irrigation hydrozone is the key parameter that is required to be measured using Option B.

The IPMVP Option A - Partially Measured Retrofit Isolation - allows some stipulated savings. This is a less-desirable method because it does not accurately measure the full impact of the measure. Option $\mathrm{C}$ ("Whole Building") and Option D ("Calibrated Simulation") are not appropriate M\&V methods for outdoor irrigation efficiency projects because they assess usage at the building level rather than the system level.

The following section provides information on the main elements of data collection that should be included in the M\&V plan when using the Option B M\&V method.

\subsection{Measure Description and Measurement Boundary}

The M\&V plan should describe the specific WCMs and the intended results. Additionally, the plan should clearly define the measurement boundary. The measurement boundary defines the specific landscaped areas that will be impacted by the WCM and monitored for water savings. 


\subsection{Baseline and Post-Installation Condition}

The M\&V plan should provide a detailed description of the baseline and post-installation conditions. It includes information related to the irrigation audit, irrigation schedule, and the condition of the landscape.

\subsubsection{Baseline Condition}

The plan should include information relevant to the baseline conditions collected during the irrigation audit. The information collected describes the state of the existing irrigation-system components such as, but not limited to, component leaks, nozzle type, and head spacing. The plan also should detail the irrigation schedule, including the type of controller and specific changes made to the irrigation schedule during the baseline year that impact the baseline water use.

The plan also should document the area of the landscape, the vegetation in the landscape, and overall landscape condition. The description of the baseline condition of the landscape can include, among other things, the landscape slope, soil type, significant drainage issues, and current planting type and condition (from aesthetic/visual quality to general plant health). The customer could require that the baseline condition be maintained in the post-installation period. If this is the case, then the ESCO and WESCO should estimate the savings potential based on the required level of irrigation to maintain the landscape at the desired level.

\subsubsection{Post-Installation Condition}

The M\&V plan should specify the condition of the irrigation systems and landscapes that will be achieved through the study period per the commissioning plan (see section 6.0). This should include information on the irrigation system components and schedules. The required appearance of the landscape can also be included. The customer might require that a specific appearance of the landscape be maintained during the study period.

\subsection{Water Use Calculations}

The M\&V plan should include the procedures used to determine the baseline water use and postinstallation water use, which are used to calculate the water savings and to properly normalize the data if required. Section 5.0 of this protocol provides detailed procedures on the calculation methods. The procedures should be described in detail, and reviewed and approved by the customer.

\subsection{Data Categories}

The M\&V plan should specify the distinct categories of data that will be gathered and the methods used to gather the data. It is important for the customer to review and approve the type of data that will be used to determine water-use savings. The following describes the type of data that can be collected.

\section{- Continuous measurement using a dedicated meter}

Volume of water logged by the metering system over the measurement period. Specify the interval at which the volumetric water use will be logged. If multiple meters are in place 
that measure water use in the measurement boundary, make sure that all meters are included. Data should be gathered monthly, which is required in the normalization process (see Section 5.3).

- Flow rate determination

Hydrozone flow rate logged by a dedicated or temporary metering system over distinct periods, typically measured in gallons per minute. The plan should include the procedure to isolate the flow rate of the specific hydrozones within the measurement boundary (see Section 4.8 for additional information on flow rate determination).

- Irrigation audit to determine the irrigation precipitation rate (baseline water use only; see Section 5.1 for additional information)

o Hydrozone precipitation rate, which is the amount of water distributed to a specific area, typically measured in inches per hour.

o Landscape area that defines the irrigation coverage of the hydrozone, typically measured in square feet. The plan should specify how the irrigation area is measured (e.g., aerial map, direct measurement).

- Irrigation system's runtime logged over the measurement period

The amount of time that the irrigation system operates over the same time frame as the flow rate, measured in minutes (e.g., irrigation control system, manual logs). The runtime should be collected from irrigation controller or operator logs. The total runtime should be the sum of the total daily runtime over the measurement period for each hydrozone.

\section{- Weather data}

Evapotranspiration and precipitation data used to normalize water use. The plan should include the data source and the location of the weather data relative to the site location (see Appendix A for local ET and precipitation data sources and methods).

- Landscape area

o The total area of the landscape should be documented, typically expressed in square feet.

o The area of specific plant types identified in Table 1 in American Society of Agricultural and Biological Engineers (ASBE) Standard S6238: Cool season turf, warm season turf, annual flowers, woody plants and herbaceous perennials (wet and dry), and desert plants. (This information can be used in the normalization process, see Section 5.3.)

\subsection{Study Period}

The study period covers the total time frame that water use is monitored per the contractual arrangement for the baseline and post-installation periods. The study period should follow the established M\&V requirements of the State Performance Contracting Program. ${ }^{2}$

\footnotetext{
2 See, for example, the "State of Colorado's M\&V Guidelines for Energy Savings Performance Contracts." Nexant. June 2008. Measurement and Verification (M\&V) Guidelines for Energy Saving Performance Contracts in State of Colorado Facilities. Boulder, CO.
} 
The plan should define the baseline period. The baseline study period should be a minimum of one full irrigation season, but preferably is an average of multiple irrigation seasons. Using an average of multiple years for the baseline study period is preferable because it helps to dampen anomalies in water use

Preferable: baseline study period is an average of multiple irrigation seasons

Acceptable: baseline study period is minimum of one full irrigation season caused by operation changes, such as scheduling issues or system maintenance problems.

The plan also should define the study period for the post-installation water use measurement. In the state of Colorado, for example, ESCOs and WESCOs are required

by statute to provide a written cost savings guarantee for the first three years of the contract period. ${ }^{3} \mathrm{At}$ the agency's discretion, the savings guarantee can be extended beyond the legislatively required period. At the end of each performance year, the ESCO and WESCO are required to submit an annual M\&V report to demonstrate that the savings have occurred.

\subsection{Measurement Period}

The M\&V plan should specify the measurement period, which defines the irrigation season. For Colorado, the typical irrigation season is from mid-April through October.

\subsection{Measurement Frequency}

The measurement frequency is the number of measurements that will be collected over the measurement period to determine water-use savings. To properly normalize the data, water use should be collected monthly.

- Water use with a dedicated meter

Water use-data should be collected from the dedicated meter at least monthly, and should capture the full measurement period.

\section{- Flow rate determination}

Flow rate for each hydrozone in the measurement boundary should be measured the beginning, mid-point, and end of the measurement period to determine an average flow rate. This ensures that an accurate flow rate is determined. Flow rates can vary due to system issues such as line leaks or broken heads. It therefore is important that system leaks are detected and corrected prior to flow-rate measurement for post-installation water use determination. Additionally, it is recommended that flow rate data be collected

\footnotetext{
${ }^{3}$ Colorado Energy Performance Contracting Office. Colorado Statutes Regarding Energy Performance Contracts for State Government. Title 24 Government - State: Principal Departments: Article 30 Department of Personnel — State Administrative Support Services, Part 20 Utility Cost-Savings Measures.
} 
from a dedicated meter rather than from a controller, because a meter records the flow rate directly.

- Irrigation runtime

Runtime for each hydrozone should be collected over distinct periods from the irrigation controller or operator logs (e.g., monthly, daily).

- Precipitation rate

Precipitation rate for each hydrozone in the measurement boundary should be measured at least once during the baseline measurement period if an irrigation audit is being used to determine baseline water use. (See Section 5.1.1 for additional information.)

\subsection{Metering Equipment}

The M\&V plan should specify the metering equipment that will be used to measure water use, which should be dedicated meters that monitor only the irrigated landscape within the measurement boundary. An existing dedicated meter can be used to determine the baseline water use, and can be customer owned or provided by the water utility.

It is important that the meter(s) used to determine the water use are calibrated. Uncalibrated meters can under-record or over-record water use and therefore can underestimate or overestimate the water use. The ESCO and WESCO should provide the method used to calibrate the meters and provide a calibration certificate to the customer. The certificate should follow the established M\&V requirements of the state performance contracting program. If there are potential metering inaccuracies, then the ESCO and WESCO should follow any established dispute-resolution steps relevant to this issue that are identified in the state performance contracting program.

For post-installation water-use measurement, the $M \& V$ plan should provide detailed information on the metering equipment, including the manufacturer, model number, and quantity being installed as part of the measure. The M\&V plan also should provide the metering equipment's installation procedure that includes the length of straight pipe required. The following meter information should be provided in the M\&V plan.

- Volumetric resolution (e.g., within 0.1 gallons)

- Accuracy range at specified ranges of flow rates

- Flow range

- Durability of construction to protect against high pressure and corrosion (e.g., plastic versus brass)

- Water-quality requirements (e.g., filtered versus unfiltered water)

- $\quad$ Line size

- Minimum and maximum operating pressure 
- Calibration method and frequency to ensure that the post-installation water use is accurately determined

The M\&V plan also should provide the type of data-management system that will log water use. The following data-management options should be considered when selecting an appropriate metering system.

- Data-logging capability that enables collection of volumetric water use over distinct periods (such as 15-minute or 1-hour intervals)

- Web-enabled interface with secure data-storage options

- Automated software updates that patch programming issues

- Capability to interface with other building-automation systems

- Customizable data forms and trending options that allow for short- and long-term graphing of data to evaluate operational issues

\subsection{Water Savings Calculations}

This section of the document provides the procedures that are used to calculate water savings. The general water savings equation is:

Water Use Savings $=($ Baseline Water Use - Post Installation Water Use $) \pm$ Adjustments

Where:

Baseline Water Use = Irrigation water use of the existing system prior to WCM implementation Post Installation Water Use = Irrigation water use after implementation of WCM

Adjustments $=$ Factor applied to normalize water use when appropriate

\subsection{Baseline Water Use}

This section describes methods to determine the baseline water use and the required normalization of the baseline.

\subsubsection{Baseline Water Use Determination}

The following options can be used to estimate baseline water use, listed in order of accuracy.

1. Continuous measurement using dedicated meter(s). If the existing irrigation system has a flow meter that monitors water use for the measurement boundary, metered data should be collected to

Preferable: Continuous measurement using dedicated meter(s)

Acceptable: Flow-rate determination

Irrigation audit to determine system precipitation rate 
determine the baseline water use (see Section 4.5).

This is the preferable method because it most accurately measures water over the measurement period. If metered data is not available for the baseline, then the other options listed below can be used to supplement missing periods.

2. Flow-rate determination. If a dedicated meter is not installed on the existing system or does not record volumetric data, then flow rates for each hydrozone - logged by a dedicated or temporary metering system within the measurement boundary - can be determined using a temporary meter or other procedure that is agreed upon in the M\&V plan. The flow rate for each hydrozone is multiplied by the hydrozone's runtime to determine the volume of water used for each hydrozone. The total baseline irrigation water use is the sum of each hydrozone's water use, represented by:

$$
\sum_{Z=1}^{n}\left(F R_{\mathrm{Z}} \times R T_{\mathrm{Z}}\right)
$$

Where:

$F R_{Z}=$ The hydrozone's flow rate, measured in gallons per minute

$R T_{Z}=$ The runtime of the hydrozone irrigation system during the baseline, measured in minutes $n=$ The total number of hydrozones

When calculating the water consumption using the flow-rate method, it is important to document the following items in the M\&V plan.

- Designate the measurement frequency for hydrozone flow rate (see Section 4.8)

- Describe how the average hydrozone flow rate was determined

- Describe how the irrigation runtime was collected over the baseline

3. Irrigation audit to determine system precipitation rate. If metering the baseline water use or using flow rates to calculate the baseline is not an option, then the third most-accurate approach is to perform an irrigation audit. An irrigation audit measures the precipitation rate of each irrigation hydrozone by capturing and measuring the amount of water distributed by the irrigation system, typically measured in inches per hour. The irrigation audit should follow the protocol set in the Irrigation Association's Recommended Audit Guidelines ${ }^{4}$ or in the American Society of Agricultural and Biological Engineers (ASBE) Standard S626 Landscape Irrigation System Uniformity and Application

\footnotetext{
${ }^{4}$ Irrigation Association. Recommended Audit Guidelines. September 2009. Available at: https://www.irrigation.org/uploadedFiles/Certification/CLIA-CGIA AuditGuidelines.pdf.
} 
Rate Testing. ${ }^{5}$ The precipitation rate for each hydrozone is applied to the hydrozone's runtime and the landscape area that the hydrozone covers. The total baseline irrigation water use is the sum of the hydrozone's water use, represented by:

$$
\sum_{Z=1}^{n}\left(P R_{\mathrm{Z}} \times A_{\mathrm{Z}} \times R T_{\mathrm{Z}} \times 0.0104\right)
$$

Where:

$P R_{Z}=$ The hydrozone's precipitation rate, measured in inches per hour

$A_{z}=$ The hydrozone's irrigation area, measured in square feet

$R T_{z}=$ The runtime of the irrigation system during the baseline period, measured in minutes

$0.0104=$ A conversion factor that converts precipitation rate and hydrozone square footage to gallons

$n=$ The total number of hydrozones

Irrigation demand using a calibrated model can provide additional information on the baseline water use when using the three prescribed methods above. An irrigation-demand method uses ET and precipitation data to calculate the amount of water needed to maintain a healthy landscape for a given location, based on the amount of water transpired and evaporated from the plants and the precipitation received at that location. Determining the irrigation demand of specific landscapes can provide critical information on the overall performance of the current irrigation system by comparing the actual water use to the water requirements of the landscape. This information can provide insight on the water-savings potential. The irrigation demand method, however, should not be used solely to estimate the baseline because it does not accurately reflect actual water use.

The ASBE Standard S623, Determining Landscape Water Demands ${ }^{6}$ is the preferred method for determining the irrigation demand. The M\&V plan should clearly state all the assumptions that are used in this method.

\subsubsection{Baseline Normalization}

If the existing irrigation is scheduled with a conventional system that irrigates based on a set "clock" schedule for which adjustments are not made, then the baseline water use should not be normalized. However, the baseline water use should be normalized (see Section 5.3 for the normalizing procedure) under the following circumstances.

\footnotetext{
${ }^{5}$ American Society of Agricultural and Biological Engineers Standard S626. Landscape Irrigation System Uniformity and Application Rate Testing. October 2016.

${ }^{6}$ American Society of Agricultural and Biological Engineers Standard S623. Determining Landscape Water Demands. January 2017.
} 
- The existing irrigation controller is a weather-based or soil-moisture-based controller that uses live data to adjust the irrigation schedule based on actual conditions.

- There are existing weather sensors, such as rain or wind gauges, that use live data to adjust the irrigation schedule based on actual conditions.

- The irrigation schedule is routinely monitored and adjusted by grounds maintenance staff. The system has a flow meter that shows water-use fluctuations throughout the irrigation season that reflect these adjustments.

\subsection{Post-Installation Water Use Determination}

As part of the requirements of using an IPMVP Option B $M \& V$ method, a meter is required to measure the postinstallation water use over the measurement period. The two options for determining the post-installation water use are described below, listed in order of accuracy.

Preferable: Continuous measurement using dedicated meter(s)

Acceptable: Flow rate determination

\section{Continuous measurement using dedicated meter(s).}

In-line meter(s) should be connected to a centralized control system or a data logger to continuously record water-use data over the study period within the measurement boundary. This is the preferable method because it most accurately measures water over the measurement period.

2. Flow-rate determination. If the dedicated meter(s) cannot accurately determine the water use of the measurement boundary, then the flow rates of the hydrozones within the measurement boundary can be used to estimate water use. (See Section 4.8 for additional information.) The flow rate for each hydrozone is multiplied by the hydrozone runtime to determine the volume of water used for each hydrozone. The total post-installation irrigation water use is the sum of hydrozone's water use, represented by the following.

$$
\sum_{Z=1}^{n}\left(F R_{\mathrm{Z}} \times R T_{\mathrm{Z}}\right)
$$

Where:
$F R_{Z}=$ The hydrozone's flow-rate, measured in gallons per minute
$R T_{Z}=$ The runtime of the hydrozone irrigation system over the study period, measured in minutes
$n=$ The total number of hydrozones

When calculating the water consumption using the spot-measurement method, it is important to document the following items in the M\&V plan.

- Designate measurement frequency for hydrozone flow rate (see Section 4.8) 
- Describe how the average hydrozone flow rate was determined

- Describe how the irrigation runtime was collected over the measurement period

Post-Installation Normalization

Post-installation water use will be normalized only if the WCMs includes a weather-based control system or weather-sensing technology that adjusts the irrigation schedule for weather changes. See Section 5.3 for detailed normalization procedures.

\subsection{Data Normalization}

As described in Sections 5.1.2 and 0, irrigation water use should be normalized if the irrigation schedule is altered for weather changes. For example, if a drought occurs during the measurement period, then the landscape will need more water to survive because of reduced rainfall. Conversely, weather can be abnormally wet if more precipitation than normal is received, thus decreasing irrigation demand. In these cases, the water use should be normalized to be commensurate with water used during a typical irrigation season.

The normalization method accounts for variations in the weather and adjusts water use to historical average weather patterns, also referred to as "climate normal." Climate normal weather data is considered average weather conditions for a given location. This is defined by the National Oceanic and Atmospheric Administration (NOAA) National Climate Data Center as the "latest three-decade averages of climatological variables."7

The historical average (climate normal) ET and effective precipitation can provide an estimate of the typical irrigation requirements of a landscape and thereby can be used to normalize water use. Evapotranspiration is the combination of loss of water due to evaporation from soil and plant surfaces and the amount of water transpired by the plant, and typically is measured in inches over a given time frame (e.g., inches per week). Reference $\mathrm{ET}\left(\mathrm{ET}_{\mathrm{o}}\right.$ ) is the loss of water from a defined vegetation (e.g., alfalfa grass), which serves as an evaporative index by which ET can be predicted for a range of vegetation types. The ET of the vegetation is determined by applying a plant factor to $E T_{0}$. The plant factor is the fraction of $\mathrm{ET}_{\mathrm{o}}$ required by the plant type for acceptable appearance. For example, cool season turf has a plant factor of 0.8. Additionally, the amount of rainfall that is available to the vegetation in the landscape - known as effective precipitation - must be determined and subtracted from ETo to calculate the amount of water that must be replaced to meet plant requirements. ${ }^{8}$ The amount of effective precipitation received over the time frame is subtracted from ET requirements to determine the "net ET."

\footnotetext{
7 NOAA's National Climate Data Center. Satellite and Information Service. "NOAA's 1981-2010 Climate Normals" website, accessed at: https://www.ncdc.noaa.gov/oa/climate/normals/usnormals.html.

${ }^{8}$ American Society of Agricultural and Biological Engineers Standard S623. Determining Landscape Water Demands January 2017.
} 
This section provides the procedures that should be used to normalize irrigation water use. The method for determining water demand is described in the ASBE Standard S623, Determining Landscape Water Demands. ${ }^{8}$ This standard was used to develop the normalization methods used below.

Follow these steps to normalize the post-installation water use over the measurement-period water use. These same procedures can be used to normalize baseline water use if required (see Section 5.1.1). Note that the following procedure specifies normalizing water use over a monthly time frame. Shorter intervals (such as daily), however, can be performed if deemed beneficial.

1. Determine the average (climate normal) monthly $\mathrm{ET}_{\circ}$ and precipitation for the location over the current measurement period.

(See Appendix A for average $\mathrm{ET}_{\mathrm{o}}$ and precipitation data sources and calculation methods.)

2. Determine the current monthly $\mathrm{ET}_{\mathrm{o}}$ and precipitation for the location over the current measurement period.

(See Appendix A for approaches to determining current-year $\mathrm{ET}_{\mathrm{o}}$ and precipitation.)

3. Determine the weighted average plant factor of the measurement boundary, following these steps:

O Determine the percentage of area covered by each plant type in the measurement boundary; use plant material types identified in Table 1 in ASBE Standard S623. ${ }^{8}$

o Determine the plant factor for each of these plant types using Table 1 in ASBE Standard S623 (use the method in this standard to calculate the adjusted plant factors for areas that are not densely planted). ${ }^{8}$

o For each plant type, multiply the plant factor by the percent area and sum these values. This provides the weighted average plant factor, represented in:

$$
\sum_{n=1}^{n}(\text { Plant Factor } \times \text { Percent Area })
$$

4. Determine the ET of the measurement boundary for the average (climate normal) and current measurement period by multiplying the weighted average plant factor by the $\mathrm{ET}_{0}$, represented in:

Monthly Average ET (inches) $=($ Weighted Average Plant Factor $\times$ Mothly Average ET $T_{\mathrm{o}}$ )

Monthly Measurement Period ET (inches) $=($ Weighted Average Plant Factor $\times$ Monthly Measurement Period ET ${ }_{\mathrm{o}}$ ) 
5. Determine the effective precipitation for the average and current monthly precipitation data over the measurement period. Effective precipitation is considered the amount of rainfall that is stored in the soil and available to the plant's root zone. ${ }^{9}$ Effective precipitation can be obtained from the United States Department of Agriculture Soil Conservation Service Part 623 National Engineering Handbook, Chapter 2: Irrigation Water Requirements, Table 2-43. ${ }^{10}$ This table provides the average monthly effective precipitation, knowing the mean monthly precipitation and average ETo. This handbook also offers a more detailed method to determining effective precipitation that includes other important parameters, such as soil type. This more detailed approach can be used if deemed necessary.

6. Calculate the historical average (climate normal) monthly net ET by subtracting local monthly historical average effective precipitation (climate normal) from monthly average ET to determine the monthly net ET, represented in this formula.

Monthly Average Net ET (inches) $=($ Monthly Average ET Monthly Average Effective Precpitation)

7. Calculate the current measurement period monthly net $\mathrm{ET}_{0}$ by subtracting local monthly current effective precipitation from monthly ET during the measurement period to determine the monthly net ET, represented in this formula.

Monthly Measurement Period Net ET (inches) = (Monthly Measurement Period ET Monthly Measurement Period Effective Precpitation)

8. Determine the monthly ratio of monthly average net ET to the current monthly measurement period net ET, represented in this formula.

Monthly Net ET Ratio $=($ Monthly Average Net ET $\div$ Monthly Measurement Period Net ET)

9. Gather the post-installation water use for each month from metered data collected during the study period.

10. Normalize each month's water use by multiplying the monthly post-installation water use by monthly net ET ratio. Then sum the monthly values to determine the total post-installation water use, represented in:

\footnotetext{
${ }^{9}$ FOA. Irrigation Water Management Chapter 3: Effective Rainfall. http://www.fao.org/docrep/s2022e/s2022e03.htm.

${ }^{10}$ United States Department of Agriculture Soil Conservation Service Part 623 National Engineering Handbook, Chapter 2. https://www.wcc.nrcs.usda.gov/ftpref/wntsc/waterMgt/irrigation/NEH15/ch2.pdf.
} 


$$
\sum_{n=1}^{n}(\text { Monthly Post-Installation Water Use } \times \text { Monthly Net ET Ratio) }
$$

Table 1 below provides an example of this normalization method. This example depicts an irrigated landscape in Aurora, Colorado. The post-installation water use was 488,422 gallons measured by the metering system. The effective precipitation was determined to be $50 \%$. The weighted average plant factor was determined to be 0.7. Abnormally hot and dry conditions were experienced during the irrigation season, whereby the total net ET over the measurement period was 33.4 inches, compared to the historical average of 26.6 inches, giving a net ET ratio of $80 \%$. Applying this value, the normalized postinstallation water use is 390,122 gallons.

Table 1. Sample Normalization of Post-Installation Water Use in Aurora, Colorado

\begin{tabular}{|c|c|c|c|c|c|c|c|c|c|}
\hline 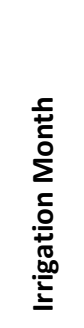 & 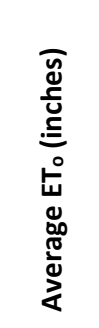 & 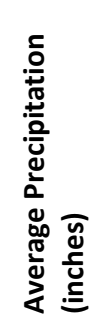 & 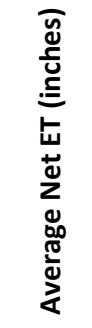 & 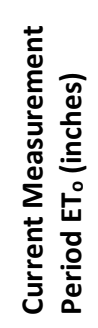 & 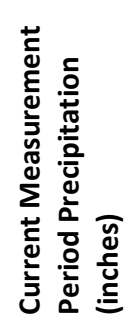 & 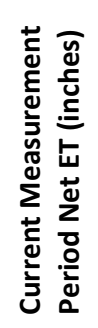 & 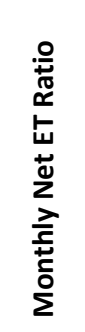 & 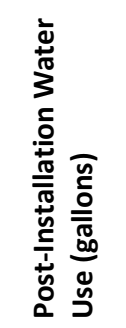 & 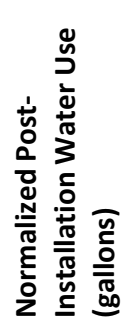 \\
\hline April & 4.86 & 1.44 & 2.74 & 5.84 & 1.33 & 3.49 & 0.79 & 29,997 & 23,551 \\
\hline May & 6.08 & 2.40 & 3.13 & 7.30 & 2.21 & 4.09 & 0.76 & 63,501 & 48,572 \\
\hline June & 7.76 & 1.37 & 4.83 & 9.31 & 1.26 & 5.99 & 0.81 & 100,369 & 80,972 \\
\hline July & 8.45 & 1.88 & 5.07 & 10.14 & 1.73 & 6.35 & 0.80 & 104,859 & 83,756 \\
\hline Aug & 7.52 & 1.36 & 4.67 & 9.03 & 1.25 & 5.79 & 0.81 & 96,934 & 78,123 \\
\hline Sept & 5.73 & 0.88 & 3.64 & 6.88 & 0.81 & 4.49 & 0.81 & 75,628 & 61,284 \\
\hline Oct & 4.05 & 0.65 & 2.55 & 4.86 & 0.60 & 3.16 & 0.81 & 17,133 & 13,865 \\
\hline Total & 44.46 & 9.98 & 26.63 & 53.36 & 9.19 & 33.35 & 0.80 & 488,422 & 390,122 \\
\hline
\end{tabular}

\subsection{Other Considerations}

The M\&V plan should state any potential issue that could significantly impact water use. If there are potential issues that might significantly impact water use, the baseline water use might need to be adjusted to account for the increased water use. The ESCO and WESCO should follow the established dispute-resolution steps identified in the State Performance Contracting Program, which should be reviewed and agreed upon between the ESCO or WESCO and the customer. Such issues can include:

- Changes to irrigation-control settings, such as local grounds maintenance crews overriding preprogrammed controllers;

- Changes in landscape area or planting type occurring at any time during the study period, which could change the irrigation requirements;

- Undetected leaks that are not repaired quickly; 
- Grounds maintenance issues such as disease of landscape that require extra watering not anticipated in the savings estimate;

- Drought management watering restrictions (and other types) imposed by the water utility, or local or state government entities that could reduce water use and change the appearance of the landscape; and

- Deficit watering during the baseline period, which is a reduction in water use as compared to the required water needs of the landscape - this could reduce the overall potential water savings of the WCM.

The annual M\&V report should provide a detailed description of any significant issue that was experienced, the subsequent impact on water use, and adjustments made to the baseline estimate as a result of the issues.

\subsection{Commissioning Protocol}

Commissioning is an important step to ensure that the water conservation measure will achieve the guaranteed savings. Commissioning is the process whereby the WCM improvements made to the irrigation equipment and control system have been verified to comply with the approved plan and visually inspected and evaluated for proper operation. Additionally, commissioning verifies that the correct irrigation schedule has been implemented for current landscape needs, and that the manager of the irrigation system has been trained to properly operate it.

Commissioning ensures that system components are functioning optimally per the measure's design and checks system performance and operational issues such as misaligned heads or leaks. A commissioning plan should be established that outlines the specific steps that will be performed. The commissioning plan should follow the Irrigation Association's "Irrigation System Inspection and Commissioning Guidelines," found in the Landscape Irrigation Best Management Practices. ${ }^{11}$ Critical components of the commissioning plan include the following.

- Qualified inspector. A commissioning agent should have the training and competencies to perform the required steps. Examples of qualifications include the Irrigation Association certifications such as Certified Landscape Irrigation Auditor, Certified Landscape Manager, Certified Irrigation Designer, ${ }^{12}$ and the Qualified Water Efficient Landscaper Program. ${ }^{13}$

\footnotetext{
${ }^{11}$ Irrigation Association and American Society of Irrigation Consultants. Landscape Irrigation Best Management Practices. March 2014. Falls Church, VA. https://www.irrigation.org/uploadedFiles/Standards/BMPDesign-InstallManage.3-18-14(2).pdf

12 Irrigation Association Certification Program:

http://www.irrigation.org/IA/Certification/IA/Certification/Certification.aspx

${ }^{13}$ Qualified Water Efficient Landscaper Program: http://www.qwel.net/
} 
- Equipment. The plan should detail the type of equipment necessary to perform the commissioning steps.

- Inspection frequency. The plan should provide the time frame of the commissioning inspection, which should be done during and after construction. It might be necessary to recommission the system within the study period to ensure that the system is operating optimally.

- Training. The plan should also include the training that is required to operate the new equipment, including training personnel on controller programming.

- Inspections and tests. The plan should specify the types of inspections and tests that will be performed to gauge the performance of the system, which can include, but are not limited to:

o Controller irrigation schedule. Ensure the controller has been properly programmed to meet the specific requirements of the landscape, which should include among other things, accounting for plant types, landscape slope, and exposure.

o Irrigation audit. Perform an irrigation audit to check the performance of the irrigation system to determine:

- Precipitation rate,

- Distribution uniformity, and

- Sensor performance.

o System tests. Conduct tests to ensure that the system meets the specifications of the design, including:

- Flow rate tests,

- Pressure tests for both high and low,

- Leak tests,

- Valve operation,

- Verification that equipment matches design plans,

- Proper head spacing, and

- Backflow prevention.

- Landscape condition assessment. Conduct an evaluation that determines the condition of the landscape, including: (see Section 4.3.2)

- Plant health, and

- Plant appearance/visual quality.

- Minimum performance requirements. The commissioning plan should specify the minimum requirements of the inspection and tests to meet the expected performance of system. 
After the commissioning has been performed, the contractor should provide a report that outlines the findings. It is recommended that the customer (or consultants) witness commissioning activities, review the commissioning report, provide comments to the ESCO or WESCO, and have comments resolved to the customer's satisfaction prior to approving the WCM. The report should include the results of all tests performed, state whether the system is functioning per the design, and list necessary corrections. 


\section{Appendix A. Local Weather Data Sources and Evapotranspiration Calculation Methods}

Precipitation and reference evapotranspiration $\left(\mathrm{ET}_{\mathrm{o}}\right.$ ) data is needed to normalize water use to a typical year, as described in Section 5.3. Precipitation data is relatively easy to locate but ET data can be more difficult to access. E Evapotranspiration is the combination of loss of water due to evaporation from soil and plant surfaces and the amount of water transpired by

Preferable: Penman-Monteith equation using climate normal weather data

Acceptable: Hargreaves equation with climate normal weather data or weather data obtained in IWMI CAWQuer database the plant, which typically is a calculated value.

The preferable method for determining $\mathrm{ET}_{\mathrm{o}}$ is the Penman-Monteith equation using climate normal weather data because it is the most accurate process. Climate normal data is considered average weather conditions over the latest three-decade period. Alternate acceptable methods for determining $\mathrm{ET}_{\mathrm{o}}$ are the Hargreaves equation with climate normal weather data or weather data obtained in the International Water Management Institute (IWMI) database, as described below.

\section{A.1 Evapotranspiration Calculation Methods}

Two common methods to calculate $\mathrm{ET}_{\mathrm{o}}$ are the Penman-Monteith and the Hargreaves equations. The Penman-Monteith equation uses daily mean temperature, wind speed, relative humidity, and solar radiation to determine $\mathrm{ET}_{0}$. The Hargreaves equation is a simplified method to estimate $\mathrm{ET}_{0}$ that only requires solar radiation and minimum and maximum temperatures over a distinct time frame (e.g., daily, weekly, or monthly).

For the purposes of normalizing water use, $\mathrm{ET}_{0}$ can be determined using either method. Generally, the Penman-Monteith method is considered more accurate because it uses multiple metrological factors to calculate to the total water losses from the reference plant. ${ }^{14}$ The simplified Hargreaves method can be used to approximate $\mathrm{ET}_{\mathrm{o}}$, however, and is appropriate to use when there is limited metrological data. ${ }^{15}$

If $\mathrm{ET}_{\mathrm{o}}$ is calculated using either of these the equations, the methods described in the following reference documents should be used, in order of preferred method.

1. Penman-Monteith equation: Chapter 4 "Determination of ETo" in the Crop Evapotranspiration - Guidelines for Computing Crop Water Requirements, produced by the

\footnotetext{
${ }^{14}$ Allen RG et al. Crop Evapotranspiration - Guidelines for Computing Crop Water Requirements. Food and Agricultural Organization for the United Nations. Rome, Italy. 1998. Accessed at: http://www.fao.org/docrep/X0490E/X0490E00.htm.

${ }^{15}$ Hargreaves GH and Allen RG. "History and Evaluation of Hargreaves Evapotranspiration Equation." Journal of Irrigation and Drainage Engineering. January 2003. Accessed at: http://onlinecalc.sdsu.edu/onlinehargreaves.pdf.
} 
Food and Agricultural Organization for the United Nations, accessed at: http://www.fao.org/docrep/X0490E/X0490E00.htm.

2. Hargreaves equation: Equation 8 listed in the "History and Evaluation of Hargreaves Evapotranspiration Equation" published in the Journal of Irrigation and Drainage Engineering, January 2003, accessed at: http://onlinecalc.sdsu.edu/onlinehargreaves.pdf.

\section{Climate Normal Data}

To determine the climate normal net $\mathrm{ET}_{0}$, climate normal data for $\mathrm{ET}_{\mathrm{o}}$ and precipitation must be collected monthly over the measurement period. This data is accessible at the National Oceanic and Atmospheric Administration (NOAA) 1981-2010 Climate Normals webpage: https://www.ncdc.noaa.gov/oa/climate/normals/usnormals.html.

\section{A.2 International Water Management Institute Data}

The International Water Management Institute database provides an alternate means for gathering average $\mathrm{ET}_{\mathrm{o}}$ instead of using the calculation methods provided above. The IWMI Climate Atlas Web Query (CAWQuer) is a web-based tool that allows users to access historical climate summary data for specified locations, assembled from weather stations worldwide and averaged from 1961 to 1990 . The dataset includes average $\mathrm{ET}_{\mathrm{o}}$ and precipitation. Even though this period is not officially considered "climate normal" because it does not span the latest three-decade time frame, this dataset is a reasonable approximation of average climate data and can be used in the normalization process described in Section 5.3.

The following sections of this appendix provide a step-by-step process for gathering data from the IWMI web-based tool. Data should be collected only over the measurement period (irrigation season) (see Section 4.7).

\section{A.2.1 IWMI Web-Based Tool Inputs}

Below is the step-by-step process for inputting information into the IWMI web-based tool.

1. Go to http://wcatlas.iwmi.org/Default.asp.

2. Register if a new user, or login if you are an existing user (see Figure A.2.1.a. IWMI Login Page). 
IWMI ON-LINE CLIMATE SUMMARY SERVICE MODEL, NOW IT'S EVEN EASIER TO GET RAPID ACCESS TO RELIABLE DATA.

The new IWMI Climate Atlas Web Query (CAWQuer) service creates online climate summaries for user-specified locations. All you have to do is enter the latitude and longitude coordinates for the location(s) you're interested in and specify which climate variables are needed. CAWQuer then searches over data in the IWMI Atlas and deliver climate summaries almost instantly. The data is displayed in an easy-to-read table, by month.

About this Model and Web based application related Queries please contact us.

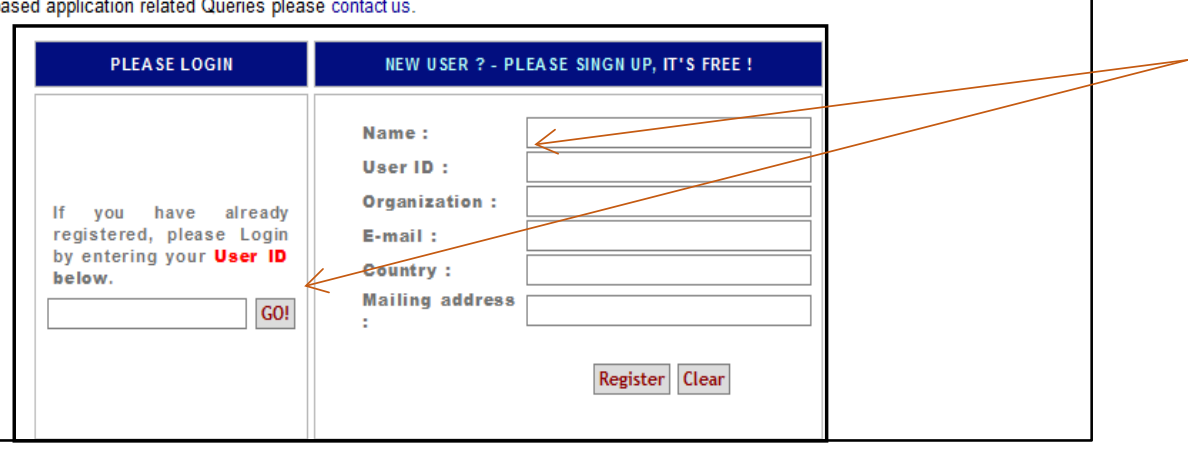

Step 1: Register or login

3. Enter site name(s). See Figure A.2.1.b. for an example of IWMI data entry for user-specified location information and climate variables available for download.

4. Enter site's latitude in degrees, minutes, seconds and whether north or south (see Section A.1.3 below for instructions on how to get site location latitude).

5. Enter site's longitude in degrees, minutes, seconds, and whether east or west (see Section A.1.3 for instructions on how to get site location latitude).

6. Climate variables to be checked are P50 $(\mathrm{mm} / \mathrm{m})$ and Penman $\mathrm{ET}_{\circ}(\mathrm{mm} / \mathrm{d})$ for normalization.

7. Click the Submit button.

Figure A.2.1.b. IWMI User-Specified Location and Climate Variables

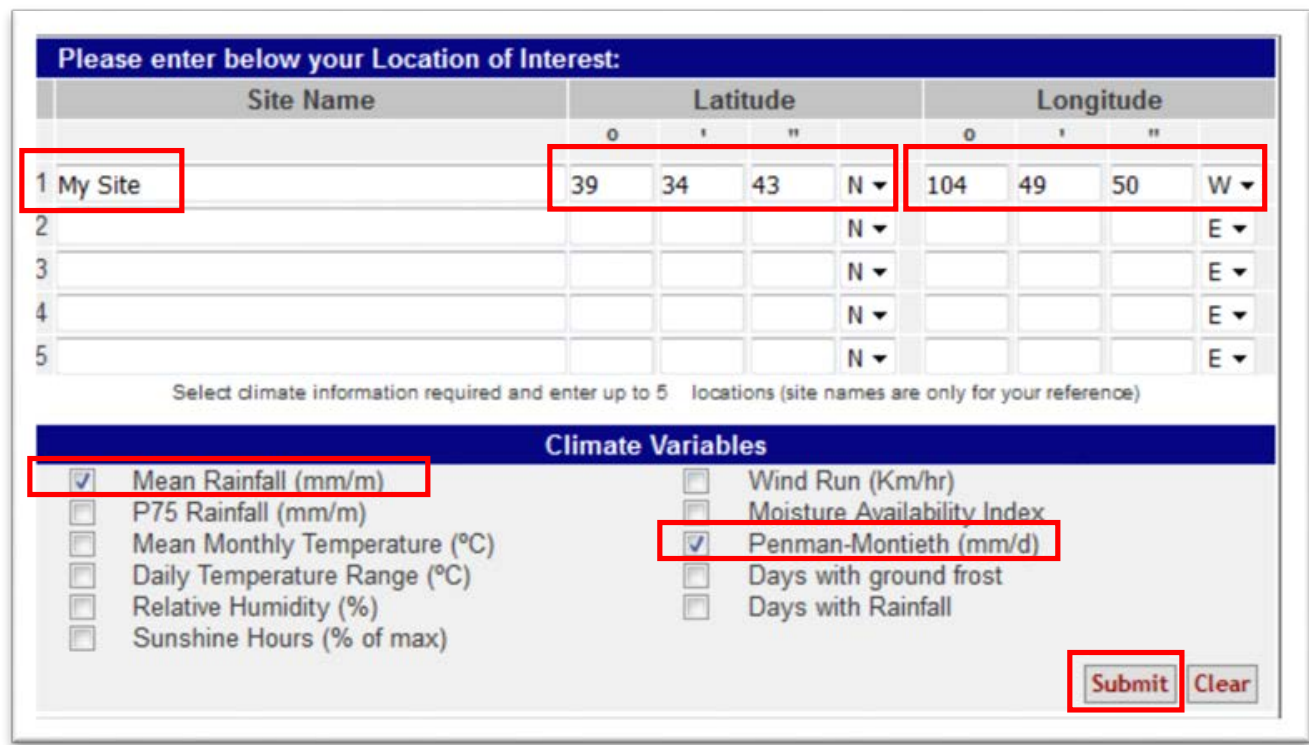




\section{A.2.2 IWMI Web-Based Tool Ouputs}

Figure A.2.2. Example of IWMI Climate Variable Outputs Needed for Normalization

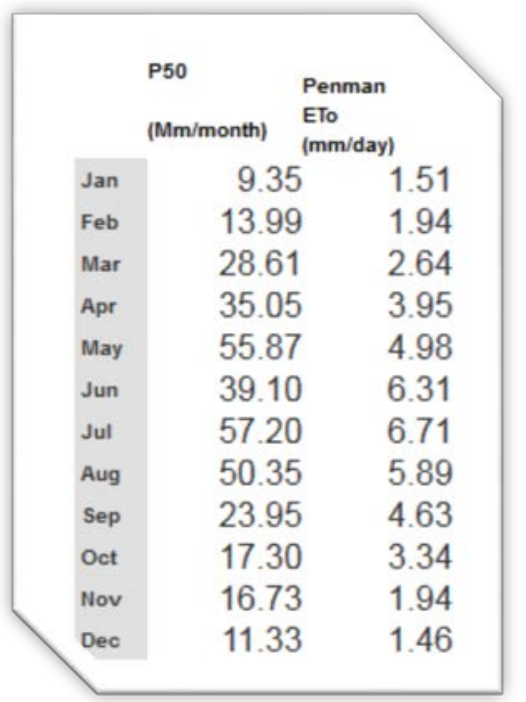

The following covers the IWMI web-based tool outputs needed for normalization as discussed in Section 5.3.

Figure A.2.2 provides an example of the climate variable outputs of the IWMI web-based tool.

a. $\quad$ P50 is the 30-year historical amount of rainfall in millimeters for the month.

b. Penman ETo is the 30-year historical reference evapotranspiration in millimeters per day. To determine monthly $\mathrm{ET}_{\mathrm{o}}$, this data is required to be converted to monthly values by multiplying the number of days in the month by the daily $\mathrm{ET}_{\mathrm{o}}$ value.

\section{A.2.3 Latitude and Longitude}

Below is a step-by-step process for obtaining latitude and longitude for a user-specified location, which is needed for the IWMI web-based tool discussed in Section A.2.1.

1. Any online latitude/longitude converter can be used (e.g. http://stevemorse.org/jcal/latlon.php).

2. Latitude and longitude format must be rendered in degrees, minutes, seconds. Also, note north, south, west, or east. Colorado: Latitude $=$ North; Longitude $=$ West.

3. See Figure A.2.3 for an example of an online latitude/longitude converter with the input and resulting output.

Figure A.2.3. Example of an Online Latitude and Longitude Converter for a User-Specified Address

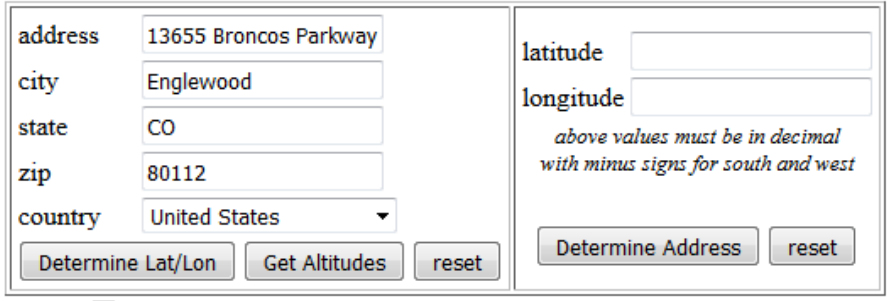

$\square$ Access geocoder.us / geocoder.ca (takes a relatively long time)
Correct format for latitude and longitude

\begin{tabular}{|l|l|l|}
\hline from google latitude & longitude & altitude \\
\hline
\end{tabular}

\begin{tabular}{|l|l|l}
\hline decimal & 39.578826 & -104.830782
\end{tabular}

deg-min-sec $39^{\circ} 34^{\prime} 43.7736^{\prime \prime} \mid-104^{\circ} 49^{\prime} 50.8152^{\prime \prime}$ 


\section{A.3 Current Weather Data Sources}

As part of the normalization process, $\mathrm{ET}_{0}$ data for the current study period must be identified. One possible data source is the Colorado Agricultural Meteorological Network's CoAgMet Crop ETo home page: http://ccc.atmos.colostate.edu/cgi-bin/extended etr form.pl. This website provides monthly ETo data for multiple weather stations across Colorado.

Other possible data sources are:

- Northern Water: http://www.northernwater.org/WaterConservation/WeatherandETInfo.aspx

- Denver Water provides a daily weather report including 24-hour total ET (inches) and historical monthly weather data for 2016 and 2017 http://www.denverwater.org/Conservation/WeatherReporting/WeatherData/

For current precipitation data, a reliable source of data can be found at NOAA's National Centers for Environmental Information, which can be accessed at: https://www.ncdc.noaa.gov/cdo-web/. 